\title{
Canadian recommendations for training and performance in basic perioperative point-of-care ultrasound: recommendations from a consensus of Canadian anesthesiology academic centres \\ Recommandations canadiennes pour la formation en et l'exécution de l'échographie ciblée périopératoire de base : recommandations d'un consensus de centres universitaires d'anesthésiologie canadiens
}

\author{
Massimiliano Meineri, MD (D) Ramiro Arellano, MD • Gregory Bryson, MD • \\ Cristian Arzola, MD • Robert Chen, MD • Peter Collins, MD • \\ Andre' Denault, MD, PhD • Georges Desjardins, MD • Ashraf Fayad, MD • \\ Duane Funk, MD • Ahmed F. Hegazy, MD • Han Kim, MD • \\ Marelise Kruger, MD • Richelle Kruisselbrink, MD • Anahi Perlas, MD • \\ Christopher Prabhakar, MD • Summer Syed, MD • Surita Sidhu, MD • \\ Robert Tanzola, MD • Adriaan Van Rensburg, MD - Hesham Talab, MD • \\ Annette Vegas, MD • Daniel Bainbridge, MD
}

Received: 23 June 2020/Revised: 7 September 2020/Accepted: 15 September 2020/Published online: 24 November 2020 (c) Canadian Anesthesiologists' Society 2020

Abstract Point-of-care ultrasound (POCUS) uses ultrasound at the bedside to aid decision-making in acute

This manuscript is related to editorial 20-00933 https://doi.org/10. 1007/s12630-020-01868-1.

\footnotetext{
M. Meineri, MD ( $\square)$

Department of Anesthesia and Intensive Care, Herzzentrum Leipzig, Struempelstrasse 39, 04289 Leipzig, Germany

e-mail: Massimiliano.Meineri@helios-gesundheit.de

Department of Anesthesiology, University of Toronto, Toronto, ON, Canada

R. Arellano, MD · R. Tanzola, MD

Department of Anesthesia, Queen's University, Kingston, ON, Canada

G. Bryson, MD · R. Chen, MD · H. Talab, MD

Department of Anesthesia, University of Ottawa, Ottawa, ON, Canada

C. Arzola, MD · H. Kim, MD · A. Perlas, MD .

A. Van Rensburg, MD · A. Vegas, MD

Department of Anesthesiology, University of Toronto, Toronto,

ON, Canada
}

clinical scenarios. The increased use of ultrasound for regional anesthesia and vascular cannulation, together with more anesthesiologists trained in transesophageal echocardiography have contributed to the widespread use of POCUS in perioperative care. Despite the support of

P. Collins, MD

Department of Anesthesia, Memorial University, Saint John, NL, Canada

A. Denault, $\mathrm{MD}, \mathrm{PhD} \cdot \mathrm{G}$. Desjardins, $\mathrm{MD}$

Department of Anesthesia, Institut de Cardiologie de Montreal, Universite' de Montreal, Montreal, QC, Canada

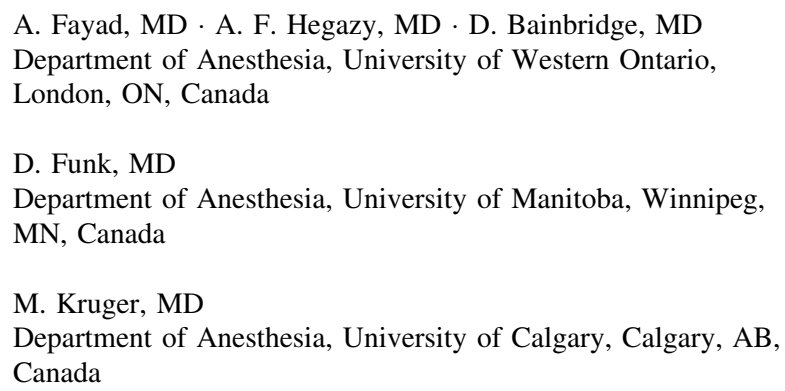


international experts, the practice of POCUS in perioperative care is variable as Canadian guidelines for anesthesiologists do not currently exist. Using a Delphi process of online surveys and a face-to-face national Canadian meeting, we developed a consensus statement for basic POCUS (bPOCUS) performance and training with a group of national experts from all Canadian universities. The group of experts consisted of 55 anesthesiologists from 12 Canadian universities considered local leaders in the field. An initial exploratory online survey of 47 statements was conducted. These statements were derived from previous generic guidelines or consensus conferences, or were based on current literature. Fourteen statements reached full consensus, 19 had 90-100\% agreement, and 14 had less than $90 \%$ agreement. Eight new statements were proposed during the national meeting, and all statements without full agreement were discussed. A second online survey included 42 modified or new statements. From this second survey, 16 statements obtained full consensus, 39 had very good agreement, and one had good agreement. The final document includes 56 statements that define the scope of practice and necessary training for perioperative bPOCUS. The statements include five bPOCUS domains: cardiac, lung, airway, gastric, and abdomen. The use of bPOCUS is evolving and will play a significant role in perioperative medicine. This consensus statement aims to define a Canadian national standard on which curricula may be based. It also provides a framework to allow further development of bPOCUS in the perioperative setting.

Résumé L'échographie ciblée (POCUS) utilise l'échographie au chevet des patients pour faciliter la prise de décisions dans les situations cliniques urgentes. L'utilisation accrue de l'échographie pour l'anesthésie régionale et la cannulation vasculaire, ainsi que l'augmentation du nombre d'anesthésologistes formés à l'échocardiographie transesophagienne, ont contribué à l'utilisation généralisée de l'échographie ciblée dans les soins périopératoires. Malgré son endossement par des experts internationaux, la pratique de l'échographie ciblée

R. Kruisselbrink, MD · S. Syed, MD

Department of Anesthesia, McMaster University, Hamilton, ON, Canada

C. Prabhakar, MD

Department of Anesthesia, University of British Columbia, Vancouver, BC, Canada

S. Sidhu, MD

Department of Anesthesia, University of Alberta, Edmonton, $\mathrm{AB}$, Canada en soins périopératoires est variable, car il n'existe pas, à l'heure actuelle, de lignes directrices canadiennes destinées aux anesthésiologistes. À l'aide d'un processus Delphi de sondages en ligne et d'une réunion nationale canadienne en personne, un groupe d'experts nationaux provenant de toutes les universités canadiennes a élaboré une déclaration consensuelle pour la formation de base en et l'exécution de l'échographie ciblée (bPOCUS). Le groupe d'experts était composé de 55 anesthésiologistes issus de 12 universités canadiennes considérés comme des chefs de file locaux dans le domaine. Un premier sondage exploratoire en ligne comportant 47 énoncés a été réalisé. Ces énoncés étaient dérivés de lignes directrices antérieures ou de conférences consensuelles, ou étaient fondés sur la littérature actuelle. Quatorze énoncés ont obtenu un consensus complet, 19 ont atteint un taux de 90 à $100 \%$, et 14 ont obtenu moins de $90 \%$ d'accord. Huit nouveaux énoncés ont été proposés au cours de la réunion nationale, et tous les énoncés n'ayant pas obtenu d'accord complet ont été discutés. Un deuxième sondage en ligne comprenait 42 énoncés modifiés ou nouveaux. Dans ce deuxième sondage, 16 énoncés ont obtenu un consensus total, 39 un très bon accord et un énoncé un bon accord. Le document final comporte 56 énoncés qui définissent le champ de pratique et la formation nécessaire pour l'échographie ciblée périopératoire de base. Les énoncés portent sur cinq domaines de l'échographie ciblée de base : échographie cardiaque, pulmonaire, des voies respiratoires, gastrique et abdominale. L'utilisation de l'échographie ciblée de base évolue et jouera un rôle important en médecine périopératoire. Cette déclaration consensuelle vise à définir une norme nationale canadienne sur laquelle les programmes d'études pourront s'appuyer. Elle fournit également un cadre pour encourager le développement ultérieur de l'échographie ciblée de base dans un contexte périopératoire.

Keywords point-of-care - perioperative management . ultrasonography $\cdot$ guideline

Point-of-care ultrasound (POCUS) is defined as the use of ultrasound (US) at the bedside by the healthcare provider attending to the patient who performs and interprets the US as an adjunct to clinical assessment to mitigate clinical uncertainty and aid clinical decision-making. ${ }^{1}$

The use of US to guide regional and neuraxial blocks as well as vascular access has become the standard of care supported by international guidelines. ${ }^{2}$ Training in US is part of the Canadian anesthesiology residency curricula, enabling the integration of skills into all recently trained anesthesiologists' armamentarium in the framework of a 
national competency-based curriculum. Similarly, transesophageal echocardiography (TEE) has become the standard of care in the intraoperative management of cardiac surgical patients. Its use is supported by Canadian ${ }^{3}$ and American ${ }^{4}$ guidelines and TEE training is integrated into cardiac anesthesiology fellowship curricula. Basic TEE training and practice has also been defined by American guidelines for use as an intraoperative hemodynamic monitor in non-cardiac surgical patients. ${ }^{5}$

The anesthesiologists' increasing familiarity with diagnostic and procedural-guiding US modalities and the wider availability of US systems including handheld devices $^{6}$ have accelerated the use of POCUS in perioperative care.

Some POCUS applications such as lung ${ }^{7}$ and focused assessment with sonography in trauma $\left(\right.$ FAST) ${ }^{8}$ have shown sensitivities and specificities comparable with those of computed tomographic scan in emergency medicine and critical care, and higher s values than those of standard chest $\mathrm{x}$-ray for diagnosing critical pathologies that often present in the perioperative period. Focused cardiac US (FCU) performed by anesthesiologists has had a significant impact on clinical decision-making and patient management in both the preoperative ${ }^{9}$ and intraoperative ${ }^{10}$ setting. Evidence suggests that airway ${ }^{11,12}$ and gastric $\mathrm{US}^{13}$ are new effective tools for intraoperative decision-making and can guide invasive procedures.

The use of POCUS in the perioperative and intraoperative settings has been strongly supported by numerous editorials and review papers. ${ }^{14}{ }^{16}$

International recommendations ${ }^{1,7,17}$ are available for single POCUS applications while some specialties have developed their own POCUS guidelines. ${ }^{18}$ None of the above fully describes the integrated use of POCUS applications in the perioperative setting. The current practice of perioperative POCUS is variable and limited by a number of factors, including lack of training and competence. $^{19}$

A recent survey on POCUS teaching at a postgraduate level in Canada reported significant variability in terms of curriculum, format, and scope of practice. ${ }^{20}$

This consensus statement aims to define a common national framework for the scope of practice and required training in perioperative basic POCUS (bPOCUS).

\section{Methods}

In 2016, the perioperative section of the Canadian Anesthesiologists' Society (CAS) selected a lead team of three experts in perioperative POCUS to lead an initiative oriented towards developing Canadian recommendations for training and practice of POCUS in the perioperative setting.

To reach all experts in the field across the country, the lead team contacted all anesthesia university chairs by e-mail through the Association of Canadian University Departments of Anesthesia. Each chair provided a list of recognized local experts already performing and teaching POCUS in each university (Appendix). All experts who replied and offered to participate formed the panel of experts.

This consensus statement was performed using a modified four-phase Delphi process including two rounds of online surveys, a round table discussion, and feedback on the final manuscript (Figure 1). The choice of this methodology was in line with previously published guidelines $^{1,7}$ and deemed applicable to the current setting posing the challenges of frequent meetings across the country and the broad spectrum of POCUS applications.

The leading team created a survey to identify the perioperative POCUS scope of practice for each US modality as well as competency assessment requirements. The survey consisted of statements that were based on a review of recognized published international guidelines for each US modality. For all the general statements and for the US applications for which previous guidelines were unavailable, the lead team formulated new statements.

A new literature search was performed for each previously published statement to update the scientific evidence. Literature searches were performed by a university librarian and reviewed by one expert.

For all the general statements and for the US applications for which previous guidelines were not available, new statements were formulated by the leading team.

All statements were collated into an online survey. The panel members completed the survey by e-mail. For each statement, they had the option to agree, disagree, or propose changes. At the end of the survey, there was a prompt for members to propose new statements.

After completion of the initial online survey, the group of experts met in person during the CAS annual meeting in Vancouver in June 2016. On this occasion, each statement that achieved less than full agreement was discussed and a review of new statements was proposed by the group. A transcript of the recorded meeting was used to reformulate statements for a second survey.

The revised statements were collated into a second online survey. The members of the panel of experts completed the second survey by e-mail. For each statement they had the option to agree or disagree. The agreement was graded for each statement based on the percentage of individuals in favour as follows: $0 \%$, no agreement; 0-25\%, fair agreement; 25-50\%, poor agreement; 
Figure 1 Diagram of the process to develop the current guidelines.
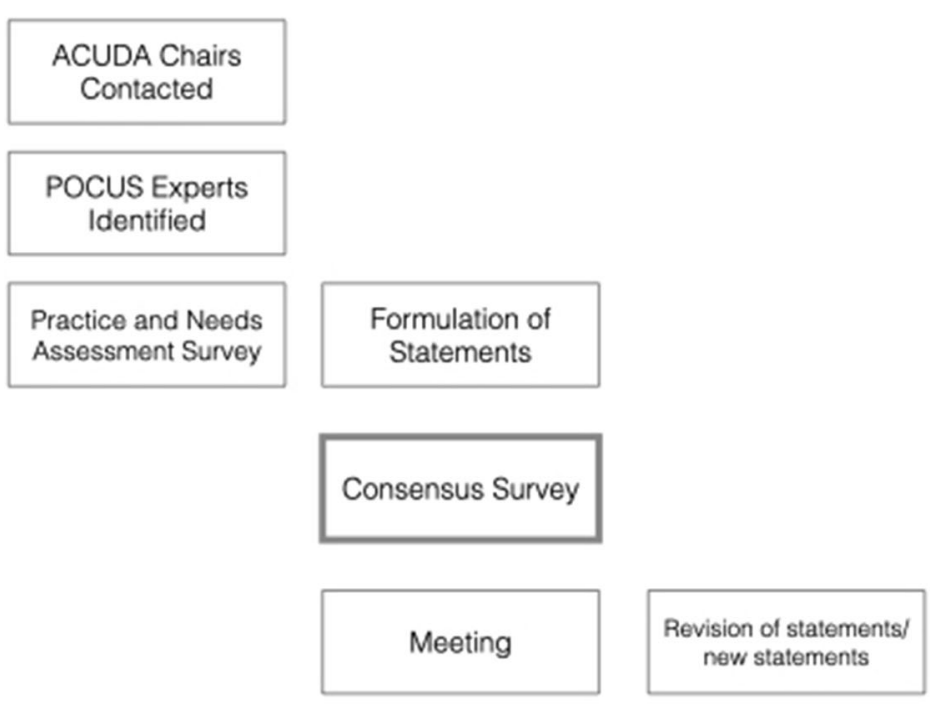

Second Consensus Survey

Draft Manuscript
Feedback on Manuscript

Revised Manuscript Submission
50-75\%, good agreement; 75-100\%, very good agreement; $100 \%$, full agreement.

Based on the first and second surveys, and the panel of experts' recommendations, a manuscript draft was completed. The draft was circulated to the panel members who had a month to provide comments and corrections. A finalized manuscript incorporating all comments and corrections was produced.

\section{Results}

The first survey included 47 statements. Fifty-five experts responded from across Canada representing 14 of the 16 university departments originally contacted across Canada. Results of the 47 statements showed 14 reached full, 19 poor, and 14 fair agreement. Eight new statements were proposed.

During the panel of experts meeting, all statements without full agreement were discussed. The panel modified 22 of the 47 original statements including all those with an agreement less than $75 \%$ and added nine new statements. This led to the creation of a second survey of 56 statements that included original, modified, and new statements. The second survey results showed 16 statements obtained full consensus (100\%), 39 very good agreement (75-100\%) and one good agreement (50-75\%).

As included in the statements, the panel of experts also agreed to define the scope of practice (Table 1) and training requirements (Table 2) for bPOCUS, leaving advanced application for further evaluation. The use of US for regional anesthesia and to guide vascular cannulation was deemed not strictly related to bPOCUS and hence was omitted from this consensus document.

The consensus document comprises 56 statements grouped into general and five specific US applications (heart, lung, gastric, airway, and abdomen).

\section{General statements}

1. Perioperative POCUS includes basic and advanced POCUS. This consensus includes bPOCUS.

(Very good agreement)

2. The pertinent areas of application of perioperative bPOCUS include (Table 1):

- Focused cardiac US

- Lung US

- Airway US

- Gastric US 
Table 1 Basic POCUS dichotomous questions per US modality defined by this consensus statement

\begin{tabular}{|c|c|}
\hline Ultrasound application & Clinical question \\
\hline Focused cardiac US & $\begin{array}{l}\text { LV dilatation } \\
\text { LV hypertrophy } \\
\text { LV dysfunction } \\
\text { RV dilatation } \\
\text { RV dysfunction } \\
\text { LA dilatation } \\
\text { MV and AV valvular abnormalities } \\
\text { Hypovolemia } \\
\text { Pericardial effusion }\end{array}$ \\
\hline Lung US & $\begin{array}{l}\text { Pneumothorax } \\
\text { Pleural effusion } \\
\text { Pulmonary edema } \\
\text { Pneumonia } \\
\text { Interstitial pneumonia } \\
\text { Diffuse parenchymal lung disease } \\
\text { Atelectasis } \\
\text { Pulmonary contusion } \\
\text { Pulmonary infarction } \\
\text { Diaphragmatic paresis }\end{array}$ \\
\hline Gastric US & $\begin{array}{l}\text { Clear fluid content } \\
\text { Clear fluid volume } \\
\text { Solid content }\end{array}$ \\
\hline Airway US & $\begin{array}{l}\text { Identification of crycothyroid membrane } \\
\text { Identification of esophageal intubation }\end{array}$ \\
\hline $\begin{array}{l}\text { Focused assessment } \\
\text { with sonography } \\
\text { in trauma }\end{array}$ & Free fluid in abdomen \\
\hline
\end{tabular}

$\overline{\mathrm{AV}}=$ aortic valve; $\mathrm{LA}=$ left atrium; $\mathrm{LV}=$ left ventricle; $\mathrm{MV}=$ mitral valve; $\mathrm{RV}=$ right ventricle; $\mathrm{US}=$ ultrasound.

- Focused assessment with sonography in trauma

(Very good agreement)

3. Basic POCUS training should include the following components:
- Introductory training

- Portfolio completion

- Competency assessment

- Quality assurance

(Full agreement)

4. Basic POCUS introductory training should include formal general POCUS learning including lectures and e-learning. ${ }^{21}{ }^{23}$ Competencies will be defined for each modality.

(Full agreement)

5. The goal of a portfolio-building phase is to provide a structured, hands-on experience to ensure a minimum level of competency and experience with POCUS. The limitations of a number-driven approach are acknowledged. While it is essential that the specific training experience be tailored to each individual learner, it is recommended that a minimum number of supervised studies be performed by the learner, as follows (Table 2):

- Basic FCU: 40 studies

- Lung and pleural US: 15 studies

- Gastric US: 20 studies

- Airway US: five studies

- Focused assessment with sonography in trauma: 20 studies

For each modality, scans with a full range of pathology should be interpreted.

(Good agreement).

6. Supervision is required during the portfolio-building phase to provide education, to continuously evaluate competency, and to ensure patient safety. The recommended approach is for US examinations to be acquired by the learner scanning in real time, with the local expert at the bedside. This allows for direct observation and immediate feedback.

(Very good agreement)

Table 2 Number of studies to be independently performed to achieve competence in bPOCUS

\begin{tabular}{lr}
\hline Ultrasound application & Number of studies \\
\hline Focused cardiac US & 40 \\
Lung US & 15 \\
Gastric US & 20 \\
Focused assessment with sonography in trauma & 20 \\
Airway US & 5 \\
\hline
\end{tabular}

bPOCUS = basic point-of-care ultrasound; US = ultrasound. 
7. Given the current limitations in the supply of local experts, it is acknowledged that an offline approach to supervision may be necessary, especially in the context of larger centres with multiple learners. In this model, the learner may digitally store videos and still images from their examinations to be reviewed at a later time with the local expert. Timely review and feedback is imperative. A blended model of both direct and offline US examination supervision may be the most realistic approach to early training. Where possible, scans performed earlier in the portfolio-building process should be prioritized for direct supervision, with offline review used more frequently as experience accrues. As the number of competent providers at a given institution increases, the number and availability of local experts to supervise portfolio training will grow in parallel. ${ }^{18}$

(Very good agreement)

8. Record keeping is required as part of the portfoliobuilding process. The method by which the portfolio is maintained will depend on each centre's resources, and may range from paper-based documentation to a more complex digital archive system. ${ }^{18}$

(Very good agreement)

9. Competency should be assessed continuously as the local expert guides the learner through the portfoliobuilding phase with timely ongoing feedback. On completion of their portfolio, each learner should also receive a final assessment that ensures competency in image acquisition, image interpretation, and clinical integration as determined by the local expert. ${ }^{18}$

(Very good agreement)

10. A quality assurance process is required for all programs to ensure that bPOCUS is being applied in a manner that consistently prioritizes patient safety. This process may take on various forms, at the discretion of the local expert, including:

- Review of archived images by the local expert and/or other external expert

- Group image review conferences

- Comparing POCUS results with those of other diagnostic modalities ${ }^{18}$

(Very good agreement)

Focused cardiac US

11. Focused cardiac US consists of obtaining five standard echocardiographic views and does not include the use of Doppler.
The views are the following:

- Parasternal long axis

- Parasternal short axis

- Apical four chamber

- Subcostal four chamber

- Subcostal inferior vena cava ${ }^{1,24}$

(Very good agreement)

12. All FCU views should be archived whenever possible.

(Full agreement)

13. Focused cardiac US is carried out to facilitate decision-making mainly in a binary (yes or no) fashion. ${ }^{1}$

(Very good agreement)

14. The following cardiac abnormalities may be accurately detected using FCU:

- Left ventricular (LV) size enlargement ${ }^{24}$

- LV hypertrophy ${ }^{24}$

- LV systolic function ${ }^{24}$

- Left atrial size enlargement ${ }^{24}$

- Right ventricular (RV) size enlargement ${ }^{24}$

- RV systolic function ${ }^{24}$

- Pericardial effusion ${ }^{24}$

- Gross valvular abnormalities ${ }^{1}$

- Inferior vena cava size ${ }^{24}$

(Good agreement)

15. The diagnosis of the following pathology is out of the scope of perioperative $\mathrm{FCU}^{1,24}$

- Aortic dissection

- Hypertrophic cardiomyopathy

- LV wall motion abnormalities

- LV aneurysm

- Cardiac masses

- Valvular vegetations

- Intracardiac shunts

(Very good agreement)

16. The aim of an FCU examination is to establish etiologies, which may include detection of gross signs of chronic cardiac disease. ${ }^{1}$

(Very good agreement)

17. The bedside decisions facilitated by FCU can generally be made by using subjective categorization of abnormalities into broad ranges of severity. Making measurements has several disadvantages during FCU. ${ }^{24}$ 
(Very good agreement)

18. Given the limitations of FCU, patients with abnormalities detected by FCU that are beyond the scope of the examination should be referred for comprehensive standard echocardiographic evaluation. ${ }^{1}$

(Full agreement)

19. Given the limitations of FCU, patients who are still suspected to have an undetected cardiac pathology should be referred for comprehensive standard echocardiographic evaluation. ${ }^{1}$

(Very good agreement)

20. Complex or unusual cardiac disorders should not be expected to be diagnosed by a physician solely trained in $\mathrm{FCU}^{24}$

(Full agreement)

21. Studies performed to evaluate a symptomatic patient to direct

management because formal echocardiography is not available,

should, in addition, include the following:

- Indication for the study

- Impression (including when a study is nondiagnostic)

- Mode of archiving the data (where can the images be found to be viewed? $)^{24}$

(Very good agreement)

22. All FCU examination results must be documented in the patient's medical record. Parameters should include the same items recorded for a physical examination:

- Date and time of examination

- Name and Hospital Identification Number of the patient

- Patient age, date of birth, and sex

- Name of the person who performed and/or interpreted the study findings ${ }^{24}$

(Very good agreement)

23. Knowledge component of FCU training comprises background topics should include:

- Ultrasound physics

- Basic cardiac anatomy

- Corresponding US views

- Pathophysiology of the common clinical conditions specifically with regard to the effects these conditions have on cardiac function and structure

- Indications for FCU vs comprehensive and/or limited echocardiography

- Limitations of FCU imaging

- Equipment

- The value of FCU in specific clinical scenarios

- Common abnormalities encountered with $\mathrm{FCU}^{24}$

(Very good agreement)

24. Imaging in normal subjects who have excellent windows and are cooperative in their positioning and respiration is a good way to learn:

- Acoustic windows

- Imaging planes

- Transducer manipulation

- Basic anatomy ${ }^{24}$

(Very good agreement)

25. The variety of pathologies experienced during handson training and expert review is likely to be a subset of the scope of pathologies and normal variants seen in the clinical setting. ${ }^{24}$

(Very good agreement)

26. A competency assessment should evaluate proficiency in:

- The appropriate safe use of the US machine

- The ability to obtain standard FCU views

- Critical evaluation of reliably interpretable images

- Identification of cardiac chambers and structures

- Pattern recognition of structural abnormalities and pathology

- Clinical integration of US findings

- The use of US information in guiding patient management ${ }^{1}$

(Very good agreement)

Lung US

27. Basic perioperative applications of lung US include the detection of:

- Pneumothorax

- Pleural effusion

- Interstitial syndrome

- Diaphragmatic paresis ${ }^{7}$

(Very good agreement)

28. In the supine patient, the sonographic technique consists of exploration of at least two anterior points, two dependent points, and the costophrenic angle on 
each hemithorax. Adjunct techniques such as M-mode and colour Doppler may be used. ${ }^{7}$

(Very good agreement)

29. The sonographic technique ideally consists of scanning eight regions. A positive region is defined by the presence of three or more B-lines in a longitudinal plane between two ribs using a scanning depth of at least $15 \mathrm{~cm}$. A positive exam result is suggested by two or more positive regions. ${ }^{7}$

(Very good agreement)

30. Lung US should be used in clinical settings when pneumothorax is in the differential diagnosis. ${ }^{7}$

(Full agreement)

31. The sonographic signs of pneumothorax include the following:

- Presence of lung point(s)

- Absence of lung sliding

- Absence of B-lines

- Absence of lung pulse ${ }^{7}$

(Full agreement)

32. Both of the following signs are present in almost all free effusions:

- A space (usually anechoic) between the parietal and visceral pleura

- Respiratory movement of the lung within the effusion ("sinusoid sign", $)^{7}$

(Full agreement)

33. A pleural effusion with internal echoes suggests that it is an exudate or hemorrhage. While most transudates are anechoic, some exudates are also anechoic. Thoracentesis may be needed for further characterization. $^{7}$

(Full agreement)

34. The optimal site to detect a non-loculated pleural effusion is at the posterior axillary line above the diaphragm. $^{7}$

(Very good agreement)

35. In opacities identified by chest radiography, lung US should be used because it is more accurate than chest radiography in distinguishing between effusion and consolidation. ${ }^{7}$

(Full agreement)

36. Sonographic B-lines can occur within a wide range of lung pathologies, the absence of B- lines effectively rules out congestive heart failure as an etiology of respiratory distress. ${ }^{7}$

(Very good agreement)

37. The differential diagnosis of interstitial syndrome is broad but may be refined by the distribution of B-lines within the lungs:

- Multiple, diffuse, bilateral B-lines may indicate:

- Pulmonary edema of various causes

- Interstitial pneumonia

- Diffuse parenchymal lung disease

- Multiple, focal B-lines, limited to a specific lung region may indicate:

- Pneumonia and pneumonitis

- Atelectasis

- Pulmonary contusion

- Pulmonary infarction ${ }^{7}$

(Full agreement)

38. Assessment of diaphragmatic movement includes:

- Diaphragm excursion

(Very good agreement)

39. The anterior subcostal approach is the preferred method for evaluating excursion. The angle of US incidence should be perpendicular to the direction of diaphragm movement. ${ }^{25}$

(Very good agreement)

40. Absence of diaphragmatic excursion $(<1 \mathrm{~cm})$ or paradoxical motion of the diaphragm is indicative of unilateral paralysis.

Normal values of left and right diaphragmatic excursion on US have been published. ${ }^{26}$

(Very good agreement)

41. Diaphragm thickness: The zone of apposition (area of the chest wall where the abdominal contents reach the lower rib cage) is assessed either qualitatively or quantitatively for a change in thickness between endinspiration and end-expiration. Lack of change in thickness is associated with unilateral diaphragm paralysis. $^{27}$

(Very good agreement)

42. A competency assessment should evaluate proficiency in:

- The appropriate use of the US machine

- The ability to obtain two-dimensional (2D) and M-mode images 
- Critical evaluation of reliably interpretable images

- Demonstration of lung sliding

- Demonstration of curtain sign

- Demonstration of diaphragmatic thickening and movement

(Very good agreement)

Airway US

43. Basic airway US is aimed at identification of the cricothyroid membrane and detection of esophageal intubation.

(Very good agreement)

44. Longitudinal and transverse US scanning techniques allow identification of the cricothyroid membrane. ${ }^{11,12}$

(Very good agreement)

45. Transverse scanning plane above the sternal notch allows identification of esophageal intubation. ${ }^{28}$

(Very good agreement)

46. Direct signs of tracheal intubation include one airmucosal interface with comet tail artifact and posterior shadowing, and two symmetrical hyperechoic lines on transtracheal US.

Indirect signs are bilateral lung sliding and equal diaphragm movement synchronized with ventilation. These signs are absent in the case of esophageal intubation. $^{28}$

(Very good agreement)

47. Signs of esophageal intubation include:

- Two air-mucosal interfaces with comet tail artifact and posterior shadowing

- Two hyperechoic lines inside the esophagus

- Opening of the esophagus by the endotracheal tube and an empty trachea. ${ }^{28}$

(Very good agreement)

48. A competency assessment should evaluate proficiency in:

- The appropriate use of the US machine

- The ability to obtain 2D images of the cricothyroid membrane and the esophagus

- Identification of esophageal intubation

(Full agreement)
Gastric US

49. Gastric US is aimed at evaluating gastric content and estimating the risk of aspiration. ${ }^{17}$

(Full agreement)

50. Gastric US provides a qualitative assessment of the nature of gastric content as:

- Empty (grade 0)

- Clear fluid content visible in the right lateral decubitus position only (grade 1)

- Clear fluid content visible in both in the supine and right lateral decubitus positions (grade 2)

- Solid content (grade 3$)^{13}$

(Full agreement)

51. Quantitative assessment of gastric clear fluid volume based on antral cross-sectional area (in the right lateral decubitus position). This helps to distinguish a negligible volume of clear fluid compatible with baseline gastric secretions $\left(<1.5 \mathrm{~mL} \cdot \mathrm{kg}^{-1} v s\right.$ a high volume in excess of normal volumes of baseline gastric secretions $\left(>1.5 \mathrm{~mL} \cdot \mathrm{kg}^{-1}\right.$

(Full agreement)

52. A competency assessment should evaluate proficiency in:

- The appropriate use of the US equipment and settings

- Recognition of appropriate indications for use

- Correct image acquisition (gastric antrum and regional landmarks including the liver, pancreas and aorta and/or inferior vena cava)

- Correct image interpretation (type of gastric content)

- Quantification of fluid volume (when appropriate)

- Correct appreciation of implications for aspiration risk and the establishment of a safe management $\operatorname{plan}^{17}$

(Full agreement)

Focused assessment with sonography in trauma

53. Focused assessment with sonography in trauma includes five views:

- Hepato-renal recess (Morrison's pouch)

- Cardiac subcostal four chamber view

- Splenorenal recess

- Bladder coronal plane

- Bladder sagittal plane ${ }^{29}$ 
(Very good agreement)

54. Focused assessment with sonography in trauma scanning is aimed at identifying free abdominal fluid. The nature of the free fluid (e.g., blood vs ascites) cannot be determined by $\mathrm{US}^{8}$

(Very good agreement)

55. When performing FAST, each view will require dynamic scanning of the anatomical spaces including probe "fanning" and "rocking". 8

(Very good agreement)

56. A competency assessment should evaluate proficiency in:

- The appropriate use of the US equipment and settings

- Recognition of appropriate indications for use

- Correct image acquisition

- Image interpretation

- Integration of FAST scanning in the trauma algorithm

(Very good agreement)

\section{Conclusions and future steps}

The growing evidence and the availability of US systems have contributed to the fast growth of POCUS in the perioperative settings. Numerous guidelines ${ }^{3}-5,8,30$ and consensus statements, ${ }^{18,21,31}$ some written by specialties outside of anesthesia and perioperative medicine, exist for single POCUS applications. Perioperative care constitutes a unique environment for the deployment of various combinations of POCUS applications. Thus, there is a need to define a clear framework for indications, techniques, and integration into decision-making. This expert consensus document aims to define the scope of practice of perioperative bPOCUS in Canada and to define national POCUS training models.

This consensus statement recognizes some of the limitations to the implementation of POCUS in the perioperative setting 20,32 and proposes alternative mentorship models. Setting a common national framework would allow consistency in training and facilitate support between different centres to allow development of common curricula to be integrated into postgraduate training.

The current consensus statement has several limitations. First, it represents a plurality of opinion from a single country rather than an extensive systematic data collection. Second, the number of studies needed to obtain competency for each exam time was not, in most cases, empirically determined.

Perioperative POCUS remains an evolving field; there will be a need in the near future for updates of current guidelines and the development of advanced POCUS guidelines. This current document sets the groundwork for a significant expansion of the anesthesiologist's scope of practice.

Author contributions Massimiliano Meineri conceived the study, analyzed the data, and wrote the first draft of the manuscript. Ramiro Arellano and Daniel Bainbridge conceived the study and contributed to editing of the manuscript. All authors contributed to editing of the manuscript.

Disclosures None.

Funding statement None.

Editorial responsibility This submission was handled by Dr. Philip M. Jones, Associate Editor, Canadian Journal of Anesthesia.

\section{Appendix}

List of Canadian POCUS experts that participated in developing the bPOCUS consensus

\begin{tabular}{ll}
\hline Members & University affiliations \\
\hline Ramiro Arellano & Queen's University \\
Daniel Bainbridge & University of Western Ontario \\
Gregory Bryson & University of Ottawa \\
Cristian Arzola & University of Toronto \\
Robert Chen & University of Ottawa \\
Peter Collins & Memorial University \\
Andre' Denault & Universite'de Montreal \\
Georges Desjardins & Universite'de Montreal \\
Ashraf Fayad & University of Western Ontario \\
Duane Funk & University of Manitoba \\
Ahmed F. Hegazy & University of Western Ontario \\
Han Kim & University of Toronto \\
Marelise Kruger & University of Calgary \\
Richelle Kruisselbrink & McMaster University \\
Massimiliano Meineri & University of Toronto \\
Anahi Perlas & University of Toronto \\
Christopher Prabhakar & University of British Columbia \\
Summer Syed & McMaster University \\
Surita Sidhu & University of Alberta \\
Robert Tanzola & Queen's University \\
Adriaan Van Rensburg & University of Toronto \\
Hesham Talab & University of Ottawa \\
Annette Vegas & University of Toronto \\
\hline &
\end{tabular}




\section{References}

1. Via G, Hussain A, Wells $M$, et al. International evidence-based recommendations for focused cardiac ultrasound. J Am Soc Echocardiogr 2014; 27(683): e1-33.

2. Troianos CA, Hartman GS, Glas KE, et al. Guidelines for performing ultrasound guided vascular cannulation: recommendations of the American Society of Echocardiography and the Society of Cardiovascular Anesthesiologists. J Am Soc Echocardiogr 2011; 24: 1291-318.

3. Beique F, Ali M, Hynes $M$, et al. Canadian guidelines for training in adult perioperative transesophageal echocardiography. Recommendations of the Cardiovascular Section of the Canadian Anesthesiologists' Society and the Canadian Society of Echocardiography. Can J Anesth 2006; 53: 1044-60.

4. Hahn RT, Abraham $T$, Adams MS, et al. Guidelines for performing a comprehensive transesophageal echocardiographic examination: recommendations from the American Society of Echocardiography and the Society of Cardiovascular Anesthesiologists. J Am Soc Echocardiogr 2013; 26: 921-64.

5. Reeves ST, Finley AC, Skubas NJ, et al. Special article: basic perioperative transesophageal echocardiography examination: a consensus statement of the American Society of Echocardiography and the Society of Cardiovascular Anesthesiologists. Anesth Analg 2013; 117: 543-58.

6. Seward JB, Douglas PS, Erbel R, et al. Hand-carried cardiac ultrasound (HCU) device: recommendations regarding new technology. A report from the Echocardiography Task Force on New Technology of the Nomenclature and Standards Committee of the American Society of Echocardiography. J Am Soc Echocardiogr 2002; 15: 369-73.

7. Volpicelli $G$, Elbarbary $M$, Blaivas $M$, et al. International evidence-based recommendations for point-of-care lung ultrasound. Intensive Care Med 2012; 38: 577-91.

8. Scalea TM, Rodriguez A, Chiu WC, et al. Focused assessment with sonography for trauma (FAST): results from an international consensus conference. J Trauma 1999; 46: 466-72.

9. Canty DJ, Royse CF, Kilpatrick D, Bowyer A, Royse AG. The impact on cardiac diagnosis and mortality of focused transthoracic echocardiography in hip fracture surgery patients with increased risk of cardiac disease: a retrospective cohort study. Anaesthesia 2012; 67: 1202-9.

10. Cowie B. Three years' experience of focused cardiovascular ultrasound in the peri-operative period. Anaesthesia 2011; 66: 268-73.

11. You-Ten KE, Desai D, Postonogova T, Siddiqui N. Accuracy of conventional digital palpation and ultrasound of the cricothyroid membrane in obese women in labour. Anaesthesia 2015; 70 : 1230-4.

12. Kristensen MS, Teoh WH, Rudolph SS, Hesselfeldt R, Borglum J, Tvede MF. A randomised cross-over comparison of the transverse and longitudinal techniques for ultrasound-guided identification of the cricothyroid membrane in morbidly obese subjects. Anaesthesia 2016; 71: 675-83.

13. Perlas A, Mitsakakis N, Liu L, et al. Validation of a mathematical model for ultrasound assessment of gastric volume by gastroscopic examination. Anesth Analg 2013; 116: 357-63.

14. Janelle GM, London MJ. Perioperative ultrasound: the future is now. Anesth Analg 2016; 122: 1734-6.

15. Ramsingh D, Gudzenko V, Martin RD. Point-of-care ultrasound: novel technology to routine perioperative assessment tool. Anesth Analg 2017; 124: 709-11.

16. Skubas NJ. Teaching whole body point-of-care ultrasound: advancing the skills of tomorrow's anesthesiologists. Anesthesiology 2015; 123: 499-500.
17. Perlas A, Van de Putte P, Van Houwe P, Chan VW. I-AIM framework for point-of-care gastric ultrasound. $\mathrm{Br} \mathrm{J}$ Anaesth 2016; 116: 7-11.

18. Arntfield $R$, Millington $S$, Ainsworth $C$, et al. Canadian recommendations for critical care ultrasound training and competency. Can Respir J 2014; 21: 341-5.

19. O'Daniel JM, McLaughlin HM, Amendola LM, et al. A survey of current practices for genomic sequencing test interpretation and reporting processes in US laboratories. Genet Med 2017; 19: $575-82$.

20. Mok D, Schwarz SK, Rondi K. Point-of-care ultrasonography in Canadian anesthesiology residency programs: a national survey of program directors. Can J Anesth 2017; 64: 1023-36.

21. Expert Round Table on Ultrasound in ICU. International expert statement on training standards for critical care ultrasonography. Intensive Care Med 2011; 37: 1077-83.

22. Vegas A, Meineri $M$, Jerath A, Corrin M, Silversides $C$, Tait G. Impact of online transesophageal echocardiographic simulation on learning to navigate the 20 standard views. J Cardiothorac Vasc Anesth 2013; 27: 531-5.

23. The Association of Anaesthetists of Great Britain \& Ireland; The Royal College of Anaesthetists; Intensive Care Society. Ultrasound in Anesthesia and Intensive Care: a guide to training 2011. Available from URL: https://anaesthetists.org/ Portals/0/PDFs/Guidelines\%20PDFs/Guideline_ ultrasound_anaesthesia_intensive_care_guide_ training_2011_final.pdf?ver=2018-07-11-163758-490 \&ver=2018-07-11-163758-490 (accessed September 2020).

24. Spencer KT, Kimura BJ, Korcarz CE, Pellikka PA, Rahko PS, Siegel RJ. Focused cardiac ultrasound: recommendations from the American Society of Echocardiography. J Am Soc Echocardiogr 2013; 26: 567-81.

25. Sferrazza Papa GF, Pellegrino GM, Di Marco F, et al. A review of the ultrasound assessment of diaphragmatic function in clinical practice. Respiration 2016; 91: 403-11.

26. Zeitoune R, Koifman AC, Fong MS, Mogami R. Ultrasound evaluation of diaphragmatic dysfunction. Radiol Bras 2017; 50: 410-1.

27. Lloyd T, Tang YM, Benson MD, King S. Diaphragmatic paralysis: the use of $\mathrm{M}$ mode ultrasound for diagnosis in adults. Spinal Cord 2006; 44: 505-8

28. Chou EH, Dickman E, Tsou PY, et al. Ultrasonography for confirmation of endotracheal tube placement: a systematic review and meta-analysis. Resuscitation 2015; 90: 97-103.

29. Dolich MO, McKenney MG, Varela JE, Compton RP, McKenney $K L$, Cohn SM. 2,576 ultrasounds for blunt abdominal trauma. J Trauma 2001; 50: 108-12.

30. Fagley RE, Haney MF, Beraud AS, et al. Critical care basic ultrasound learning goals for American anesthesiology critical care trainees: recommendations from an expert group. Anesth Analg 2015; 120: 1041-53.

31. Mayo PH, Beaulieu Y, Doelken P, et al. American College of Chest Physicians/La Societe de Reanimation de Langue Francaise statement on competence in critical care ultrasonography. Chest 2009; 135: 1050-60.

32. Dinh VA, Fu JY, Lu S, Chiem A, Fox JC, Blaivas M. Integration of ultrasound in medical education at United States medical schools: a national survey of directors' experiences. J Ultrasound Med 2016; 35: 413-9.

Publisher's Note Springer Nature remains neutral with regard to jurisdictional claims in published maps and institutional affiliations. 